\title{
Impact of Mountains on Tropical Circulation in Two Earth System Models ${ }^{\mathscr{A}}$
}

\author{
ZACHARY NAIMAN AND PAUL J. GOODMAN \\ Department of Geosciences, The University of Arizona, Tucson, Arizona \\ JOHN P. KRASTING \\ NOAA/Geophysical Fluid Dynamics Laboratory, Princeton, New Jersey \\ Sergey L. MALYSHEV \\ Department of Ecology and Evolutionary Biology, Princeton University, Princeton, New Jersey \\ JOELLEN L. RUSSELL \\ Department of Geosciences, The University of Arizona, Tucson, Arizona \\ RONALD J. STOUFFER AND ANDREW T. WiTTENBERG \\ NOAA/Geophysical Fluid Dynamics Laboratory, Princeton, New Jersey
}

(Manuscript received 13 July 2016, in final form 7 February 2017)

\begin{abstract}
Two state-of-the-art Earth system models (ESMs) were used in an idealized experiment to explore the role of mountains in shaping Earth's climate system. Similar to previous studies, removing mountains from both ESMs results in the winds becoming more zonal and weaker Indian and Asian monsoon circulations. However, there are also broad changes to the Walker circulation and El Niño-Southern Oscillation (ENSO). Without orography, convection moves across the entire equatorial Indo-Pacific basin on interannual time scales. ENSO has a stronger amplitude, lower frequency, and increased regularity. A wider equatorial wind zone and changes to equatorial wind stress curl result in a colder cold tongue and a steeper equatorial thermocline across the Pacific basin during La Niña years. Anomalies associated with ENSO warm events are larger without mountains and have greater impact on the mean tropical climate than when mountains are present. Without mountains, the centennial-mean Pacific Walker circulation weakens in both models by approximately $45 \%$, but the strength of the mean Hadley circulation changes by less than $2 \%$. Changes in the Walker circulation in these experiments can be explained by the large spatial excursions of atmospheric deep convection on interannual time scales. These results suggest that mountains are an important control on the large-scale tropical circulation, impacting ENSO dynamics and the Walker circulation, but have little impact on the strength of the Hadley circulation.
\end{abstract}

\section{Introduction}

Land surface topography is a fundamental boundary condition of Earth's climate system. As such, there is a greater than 40-yr history of numerical modeling

Supplemental information related to this paper is available at the Journals Online website: http://dx.doi.org/10.1175/JCLI-D-16-0512.s1.

Hominin Sites and Paleolakes Drilling Project Publication Number 9.

Corresponding author e-mail: Zachary Naiman, znaiman@ arizona.edu experiments that examine the role of orography in shaping broad features of the climate system. Previous studies have used a paleo approach in which orographic height and location correspond to best estimates of continental configurations and orography from specific periods in Earth's history (e.g., Barron and Washington 1984); a regional approach, in which the height of specific orography is varied (Xu et al. 2004; Takahashi and Battisti 2007a,b; Boos and Kuang 2010; Feng and Poulsen 2014; Maroon et al. 2015; Singh et al. 2016); and a global approach, in which the height of all of Earth's land surface topography is varied systematically (Manabe and Terpstra 1974; Kutzbach et al. 1989; 
Kutzbach et al. 1993; Manabe and Broccoli 1990; Kitoh 1997, 2004; Abe et al. 2004; Kitoh 2007; Schmittner et al. 2011; Sinha et al. 2012).

Early idealized studies that varied global orography in general circulation models were limited by computing resources and therefore carried out relatively short simulations using simplified models (e.g., atmosphereland models with no ocean component) and focused their analysis on midlatitude climates where the influence of mountains on standing atmospheric waves is strong (Manabe and Terpstra 1974). Similar studies were repeated over the following three decades as models improved in terms of their resolution in space and time, included more components of the climate system (e.g., the ocean, cryosphere, and land vegetation), and refined the physics related to subgrid parameterizations (Kutzbach et al. 1993; Kitoh 1997, 2002). Of these studies, only simulations run in the early 2000s used a fully coupled atmosphere-ocean general circulation model (AOGCM) without flux adjustments. Although these simulations, integrated for 50 model years, represented a significant advance in global climate models at the time, today's state-of-the-art Earth system models (ESMs) boast improved parameterizations, a higher component coupling frequency, and higher spatial resolutions that better resolve topographic details and improve the land-sea mask. Because of increased computing capacity, ESMs are commonly integrated for hundreds to thousands of model years, whereas earlier AOGCMs were typically integrated for tens of model years.

In this paper, we present the results of an idealized experiment in which we adopted the global approach to varying Earth's land surface topography in order to better understand the influence of mountains, at the largest scale, on the climate system. We removed all land surface topography from two state-of-the-art ESMs and ran our "PANCAKE" simulations for over 500 model years. Previous work had found that removing orography causes midlatitude westerly winds to become more zonal (e.g., Manabe and Terpstra 1974), monsoon circulation to weaken (e.g., Kitoh 2004; Lee et al. 2015), and global surface temperatures to rise by $1^{\circ}-1.5^{\circ} \mathrm{C}$ (Barron 1985; Kutzbach et al. 1993; Kitoh 1997). El Niño-Southern Oscillation (ENSO) was reported to become more regular with a higher amplitude and lower frequency without mountains (Kitoh 2007). However, because of the relatively short integration time of 50 model years, it was unclear if that result would be found in a longer experiment. With this caveat, we expected that our ESMs would give similar results to previous experiments and would allow us to diagnose changes to the climate system to an unprecedented degree. The increased model resolution and complexity of the model were expected to provide potentially new results. We were encouraged by the fact that these ESMs and their predecessor simulate ENSO very well (Wittenberg et al. 2006; Guilyardi 2006; Guilyardi et al. 2012). Additionally, these experiments would allow us to examine the role of orography in producing model biases such as the too-warm ocean current off the coast of Peru associated with the coarse representation of the Andes (Philander et al. 1996; Wittenberg et al. 2006).

Although our results are broadly consistent with previous studies, the impact of mountains on tropical climate was much more profound than we expected. The changes observed in our simulations suggest that mountains play a primary role in shaping tropical climate through their impact on ENSO and the Walker circulation. The results are exciting from a climate dynamics perspective because ENSO has a strong influence on global climate on interannual time scales. They will also be of interest to the paleoclimate community because changes to ENSO and the Walker circulation are considered to play an important role in Earth's slide into the icehouse climate since the Pliocene (Ravelo et al. 2004; Fedorov et al. 2006; Brierley and Fedorov 2010; Fedorov et al. 2013), and links between the progressive aridification of the East African rift region since the late Miocene and hominin evolution have been the subject of research for well over a century [see Domínguez-Rodrigo (2014) for a recent review].

In the next section, we describe the models and observation-based data used in this study. Section 3 examines the mean tropical circulation in the PANCAKE simulations, and section 4 explores the interannual variability. Section 5 discusses the possible role of different mountains in our results, and our conclusions are reported in section 6.

\section{Data and models}

We removed land surface topography, including ice height, from two GFDL ESMs, ESM2Mb and ESM2G, which differ only in their oceanic components (ESM2Mb uses a depth-based vertical coordinate $z^{*}$ whereas ESM2G uses an isopycnal vertical coordinate) and have identical atmosphere, ice, and land surface components (Dunne et al. 2012, 2013). These models resolve the diurnal cycle, using a 30-min time step for atmospheric variables, a 1-h time step for oceanic variables and coupling between model components, and a 3-h radiation time step (Dunne et al. 2012, 2013). Both models use a grid with $2^{\circ}$ longitude by $2^{\circ}$ latitude spacing in the atmospheric component and $1^{\circ}$ longitude by $1^{\circ}$ latitude spacing (telescoping to $1 / 3^{\circ}$ latitude spacing near the equator) in the oceanic component. The $\mathrm{ESM} 2 \mathrm{Mb}$ is very similar to the GFDL ESM2M, but the above-ground land biomass was adjusted to better match ESM2G and observations (Dunne et al. 2012, 2013). The physical climate and response to changes in forcing are very 

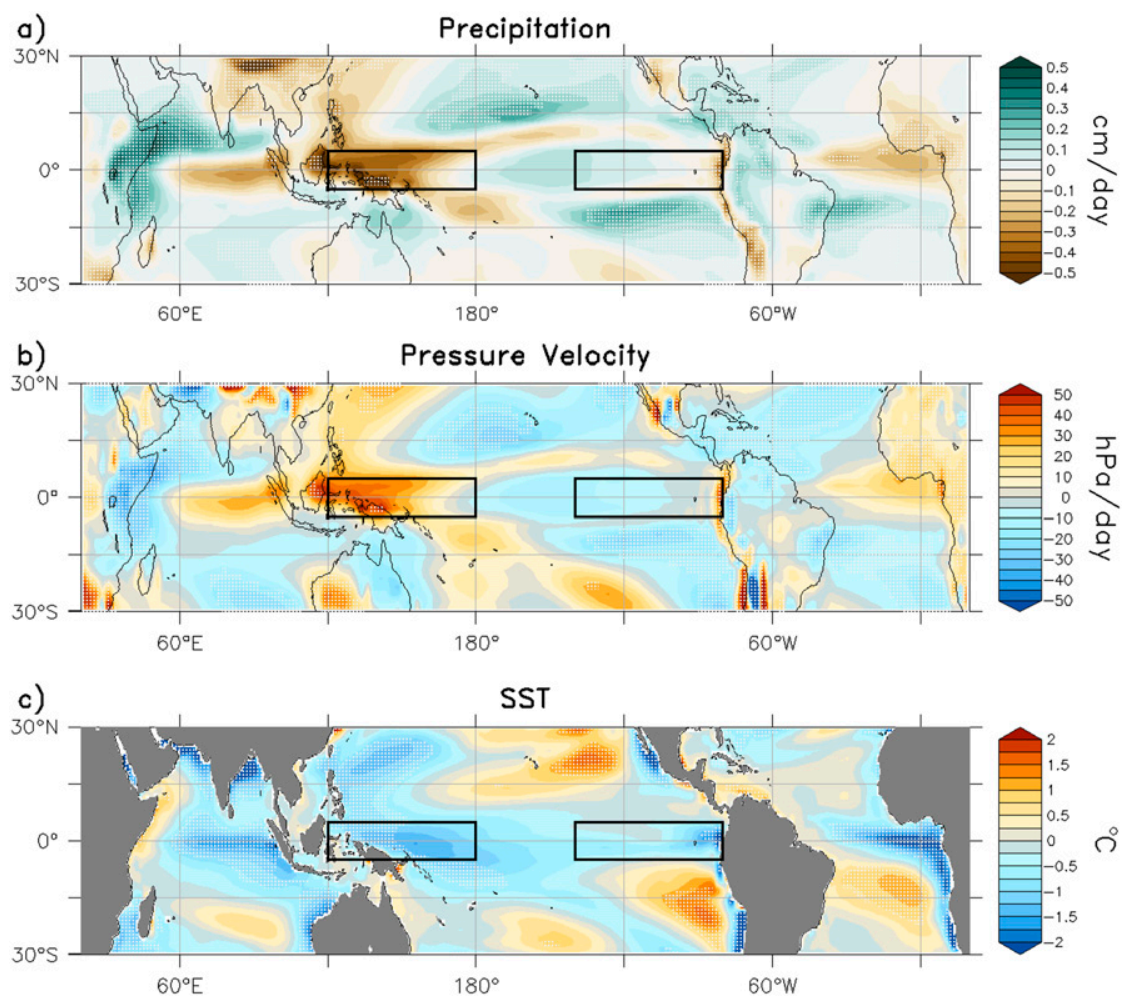

FIG. 1. Differences (PANCAKE minus CONTROL) of 100-yr means (years 401-500) for (a) precipitation, (b) $\omega$, and (c) SST. All values are from ESM2Mb. Values for $\omega$ are at $500 \mathrm{hPa}$; negative (blue) values are in the upward direction. Results for $\omega$ do not change significantly when different pressure levels, or an average of pressure levels, are used to represent the midtroposphere. Black rectangles show regions used to calculate dSLP as the difference between average sea level pressures in an equatorial region of the eastern Pacific $\left(5^{\circ} \mathrm{S}-5^{\circ} \mathrm{N}\right.$, $\left.140^{\circ}-80^{\circ} \mathrm{W}\right)$ and the western Pacific $\left(5^{\circ} \mathrm{S}-5^{\circ} \mathrm{N}, 120^{\circ} \mathrm{E}-180^{\circ}\right)$. Areas where the difference between PANCAKE and CONTROL mean values are more than two standard deviations of annual mean CONTROL values over the 100 -yr period are hatched.

similar between ESM2M and ESM2Mb. In PANCAKE, we did not change river routings, the geographic distribution of albedo associated with high-latitude glaciers (i.e., Antarctica and Greenland are white in PANCAKE, assuming an ice-sheet-covered surface, but the topography associated with glaciers was removed), ocean bathymetry, surface roughness, or sea level (ice removed from continents was not added to the ocean). Consistent with flattening model topography, the topographic momentum drag scaling scheme and the gravity wave drag scheme were both turned off in PANCAKE. Our "CONTROL" experiments were run with preindustrial radiative forcing and atmospheric chemistry.

The PANCAKE experiment was run in both ESM2Mb and ESM2G for over 500 model years, and years 401-500 are used throughout this analysis to represent the quasiequilibrium climate state, defined here as having a net radiative imbalance at the top of the atmosphere of less than $0.5 \mathrm{~W} \mathrm{~m}^{-2}$ and trends in surface air temperature of less than $0.5^{\circ} \mathrm{Ccentury}^{-1}$. We call this a quasi-equilibrium climate state because the deep ocean is not fully equilibrated with the changes in the surface forcing. Centennialscale trends in Earth's energy balance and climate variables such as surface air temperature are related to changes in the ocean's overturning circulation, which generally weakens over the course of these simulations. However, they would only have a small or no impact on the tropical dynamics presented here, which appear in the first years of the simulations and are consistent throughout the runs.

Throughout this paper, we compare our CONTROL climatological mean diagnostics with the European Centre for Medium-Range Weather Forecasts (ECMWF) interim reanalysis (ERA-Interim) product (Dee et al. 2011). For comparison with long time series of ENSO-related variables, we use ECMWF's twentieth century reanalysis (ERA-20C) product (Compo et al. 2011). The CONTROL runs for both models and the closely related GFDL CM2.1 have been reported to reproduce the broad features of Earth's climate system, and the two models tend to straddle observations for many metrics, including the ENSO 

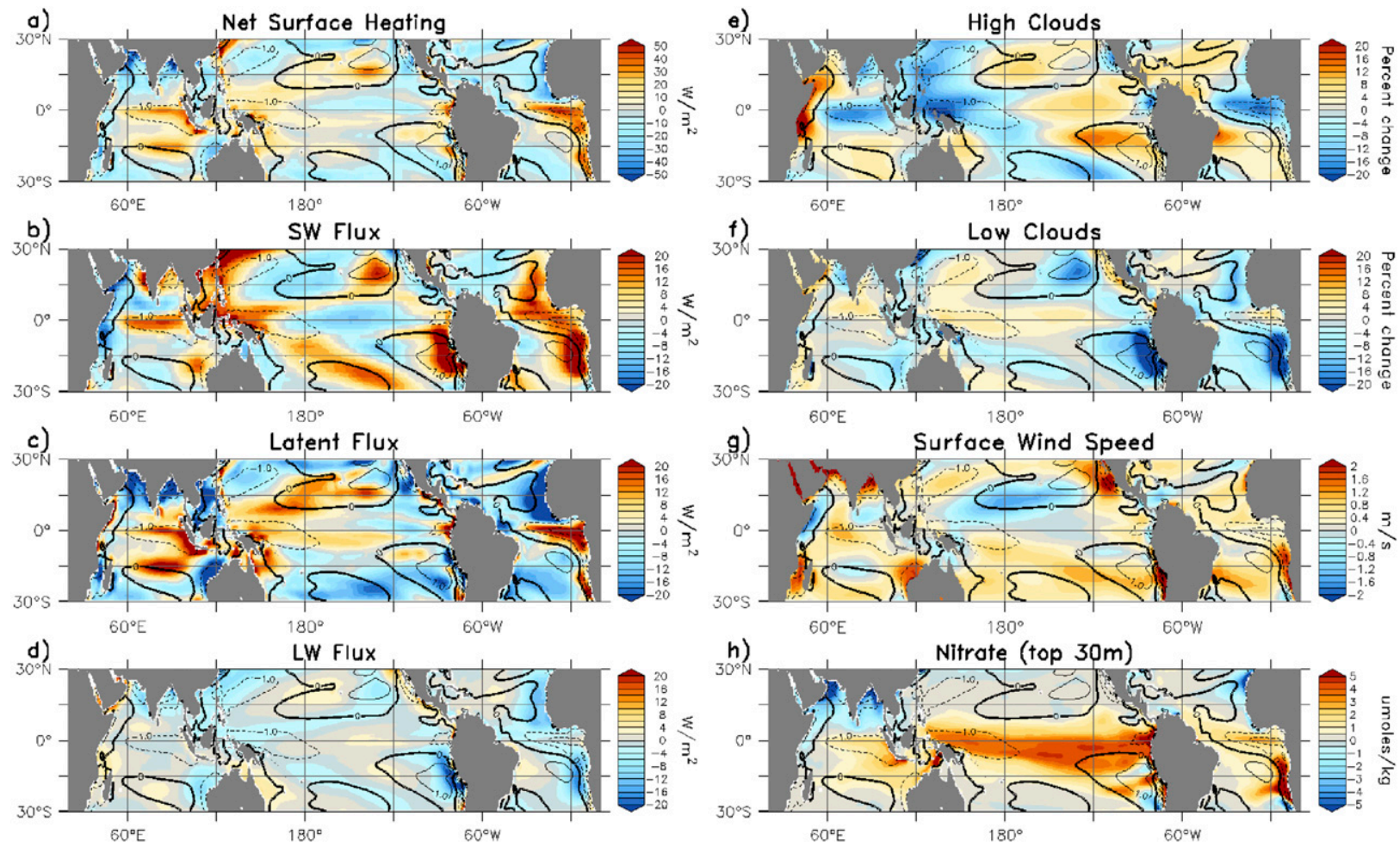

FIG. 2. Diagnostics for changes in tropical SSTs, including the dominant surface radiation flux terms. PANCAKE minus CONTROL is shown for model years 401-500, with the change in SSTs contoured $\left({ }^{\circ} \mathrm{C}\right)$, for $(\mathrm{a})$ net surface heating $\left(\mathrm{W} \mathrm{m}{ }^{-2}\right.$, positive fluxes are into the ocean $),(b)$ shortwave flux into the ocean $\left(\mathrm{W} \mathrm{m}^{-2}\right)$, (c) latent heat flux into the ocean $\left(\mathrm{W} \mathrm{m}^{-2}\right)$, (d) longwave flux into the ocean $\left(\mathrm{W} \mathrm{m} \mathrm{m}^{-2}\right.$ ), (e) high clouds (\%), (f) low clouds (\%), (g) surface wind speed $\left(\mathrm{m} \mathrm{s}^{-1}\right)$, and (h) nitrate in surface waters $\left(\mu \mathrm{mol} \mathrm{kg}^{-1}\right.$, in the top $\left.30 \mathrm{~m}\right)$.

magnitude; the ENSO frequency is close to observed values (Guilyardi 2006; Wittenberg et al. 2006; Dunne et al. 2012; Kim and Yu 2012; Dunne et al. 2013; Bellenger et al. 2014). Both models exhibit well-known biases in tropical precipitation that are common to coupled climate models, including too little rain over the Amazon region and a double intertropical convergence zone (ITCZ) characterized by too much rain in the Southern Hemisphere over the central and eastern tropical Pacific (Mechoso et al. 1995; Dai 2006; Wittenberg et al. 2006; Dunne et al. 2012). Detailed analysis of the convective schemes used in our models and precipitation biases on diurnal to interannual time scales were performed on GFDL's CM2.1 (Dai 2006; Lin et al. 2006).

The two Earth system models used in this study produced the same qualitative results when the land surface orography was removed. We focus our presentation below on the ESM2Mb results; many figures for ESM2G can be found in the supplemental material.

\section{Mean circulation}

Similar to previous studies (Manabe and Terpstra 1974; Ruddiman and Kutzbach 1989), Earth's winds are much more zonal when land surface topography is removed. Changes to the strength of the global water cycle (both precipitation and evaporation) are less than $1 \%$ in both models, and the globally averaged surface air temperatures (SAT) also exhibit small changes (PANCAKE is $0.67^{\circ} \mathrm{C}$ warmer in $\mathrm{ESM} 2 \mathrm{Mb}$ and $0.23^{\circ} \mathrm{C}$ warmer in ESM2G). The SAT change is consistent in sign with previous studies but smaller in magnitude (Barron 1985; Kutzbach et al. 1993; Kitoh 1997). Assuming a lapse rate of $6.5^{\circ} \mathrm{C} \mathrm{km}^{-1}$, the global decrease in land surface elevation of $231 \mathrm{~m}$ suggests an increase in SAT of about $1.5^{\circ} \mathrm{C}$ due to the lapse rate effect; the actual change is smaller, likely as a result of feedbacks related to changes in cloud types and distributions.

Average tropical $\left(30^{\circ} \mathrm{S}-30^{\circ} \mathrm{N}\right)$ surface air temperatures also exhibit changes that are small in magnitude $\left(0.37^{\circ} \mathrm{C}\right.$ in ESM2Mb and $0.25^{\circ} \mathrm{C}$ in ESM2G). However, the spatial pattern of tropical rainfall changes significantly in both experiments (Fig. 1). Where tropical precipitation is high (low) in CONTROL, precipitation decreases (increases) in PANCAKE. Tropical precipitation is less focused in PANCAKE, where the maximum spreads out in both the meridional and zonal directions. The ITCZ in the Southern Hemisphere is more developed in 

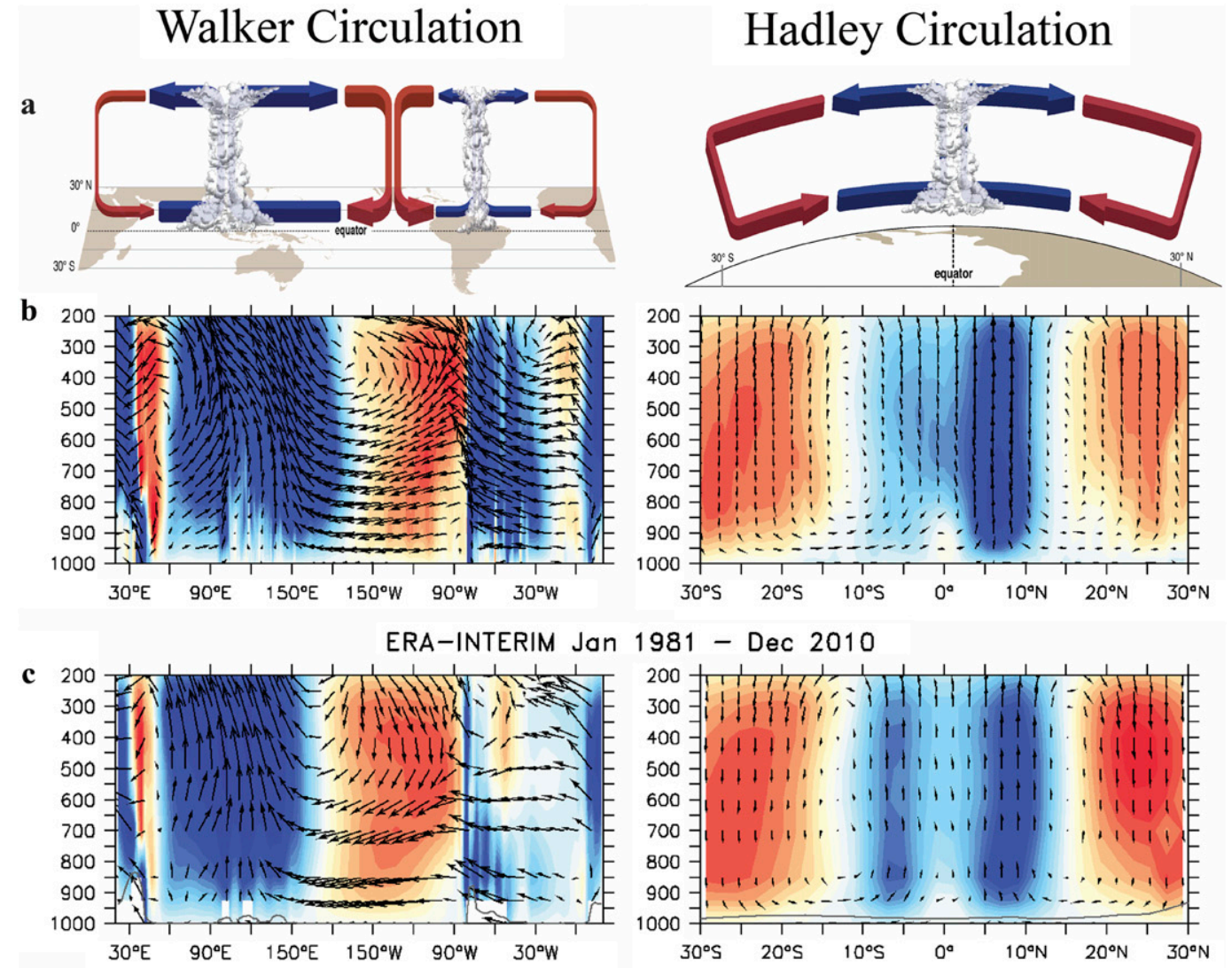

ESM2Mb CONTROL Jan 401 - Dec 500
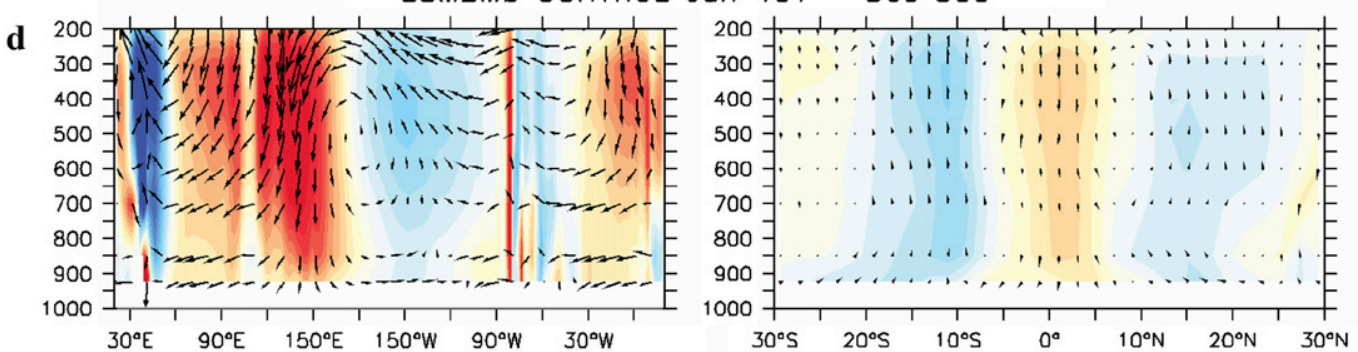

ESM2Mb PANCAKE minus CONTROL

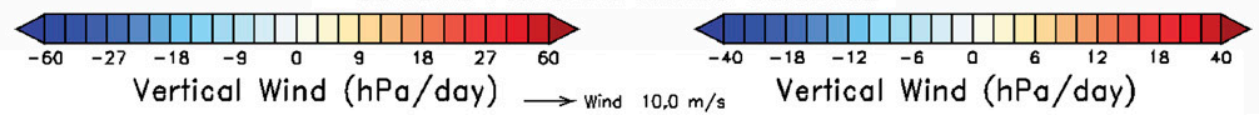

FIG. 3. Walker and Hadley circulations. The Pacific Walker circulation weakens in PANCAKE, whereas the strength of the Hadley circulation remains largely unchanged. Vertical (pressure) velocities are shaded [negative (blue) values are in the upward direction] and vectors are (left) zonal wind $\mathbf{u}$ and vertical wind $\mathbf{w}$ for Walker circulation (values are meridional averages from $5^{\circ} \mathrm{S}-5^{\circ} \mathrm{N}$ ) and (right) meridional wind $\mathbf{v}$ and vertical wind $\mathbf{w}$ for Hadley Circulation (values are zonal averages). (a) Schematic depiction of (left) Walker and (right) Hadley circulations. (b) ERA-Interim data from January 1981 to December 2010. (c) ESM2Mb CONTROL model years 401-500. (d) Difference between ESM2Mb PANCAKE (model years 401-500) and ESM2Mb CONTROL (model years 401-500). The vertical component of the wind speed vector was approximated from the pressure velocities using the relationship $w=\omega /(-\rho g)$, where $\rho$ is air density and $g$ is gravitational acceleration, and is scaled by $10^{4}$. Note the different color scales for (left) and (right). The gray curve in each panel near the abscissa shows approximate topography from observations [from $40^{\prime}$ gridded elevations/bathymetry for the world (ETOPO40) in (b)] and the respective models. 

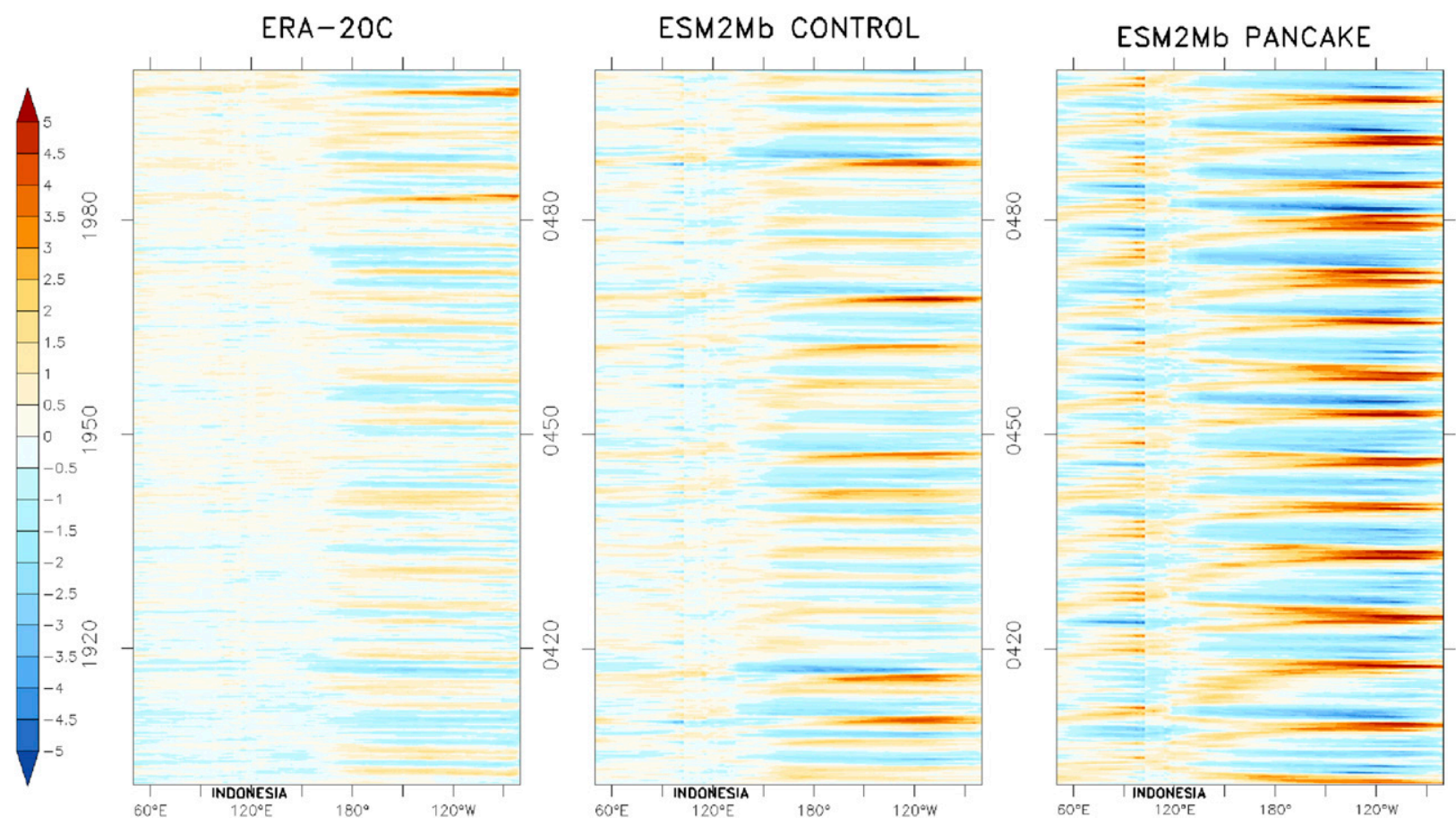

FIG. 4. Longitude-time plot of 3-month running anomalies relative to mean climate averaged over $5^{\circ} \mathrm{S}-5^{\circ} \mathrm{N}$ for SST $\left({ }^{\circ} \mathrm{C}\right)$ from $($ left $)$ ERA-20C (years 1900-2000), (center) ESM2Mb CONTROL (model years 401-500), and (right) ESM2Mb PANCAKE (model years 401-500). Time increases in the vertical direction. Longitudes cover the Indian and Pacific Ocean basins. Approximate location of Indonesia is shown below the abscissa.

PANCAKE, extending farther across the Pacific basin than in CONTROL, especially during austral summer and fall seasons. PANCAKE has less precipitation over the Maritime Continent during these seasons and more over the southern Indian Ocean. Given the "double ITCZ" bias in our CONTROL models, this tendency in the PANCAKE simulations is difficult to interpret. However, the result is consistent with the fact that the SAT increases are larger in the Southern Hemisphere in both models because the ITCZ tends toward the warmer hemisphere, such that its poleward flow aloft transports heat to the cooler hemisphere (Broccoli et al. 2006; Frierson et al. 2013; Donohoe et al. 2013; Hill et al. 2015; Bischoff and Schneider 2016). ITCZ changes may also be effected by regional changes in deep convection, especially in the southeastern subtropical Pacific, where the presence of the Andes likely suppresses deep convection (Rodwell and Hoskins 2001; Takahashi and Battisti 2007a,b; Feng and Poulsen 2014).

In PANCAKE, precipitation decreases most dramatically over the Maritime Continent (about $100^{\circ}-150^{\circ} \mathrm{E}$ ) and increases over East Africa, the central equatorial Pacific (between around $180^{\circ}$ and $110^{\circ} \mathrm{W}$ ), and most of the Amazon basin. Precipitation over India and Southeast Asia decreases, consistent with a weakened monsoon circulation. The changes to the spatial distribution of precipitation occur throughout the entirety of the tropics, including the central Pacific Ocean, and are not confined to regions of significant orography.

The changes to the spatial pattern of tropical rainfall are very similar to changes in vertical (pressure) velocity $\omega$ in the middle of the troposphere (at $500 \mathrm{hPa}$; Fig. 1). Where air rises very quickly (slowly) in CONTROL, it rises more slowly (quickly) in PANCAKE. The few exceptions to this relationship are in regions of significant topography (the central Andes, the Himalayas, and the Sierra Madre). However, these areas constitute a small proportion of the tropics, and the differences are associated with local effects of removing topography. Apart from these local effects, there is clearly a broader impact; removing orography changes the location and strength of vertical air motion far away from the location of the orography, for example in the middle of the tropical Pacific Ocean.

Tropical sea surface temperatures (SSTs) decrease slightly in both experiments $\left(-0.24^{\circ} \mathrm{C}\right.$ in ESM $2 \mathrm{Mb}$ and $-0.60^{\circ} \mathrm{C}$ in ESM2G), as do global SSTs $\left(-0.46^{\circ} \mathrm{C}\right.$ in ESM $2 \mathrm{Mb}$ and $-0.33^{\circ} \mathrm{C}$ in ESM2G). The spatial pattern of SST changes (Fig. 1) is distinct from the precipitation and $\omega$ anomaly patterns. For example, surface waters cool significantly to the east and west of the Maritime 

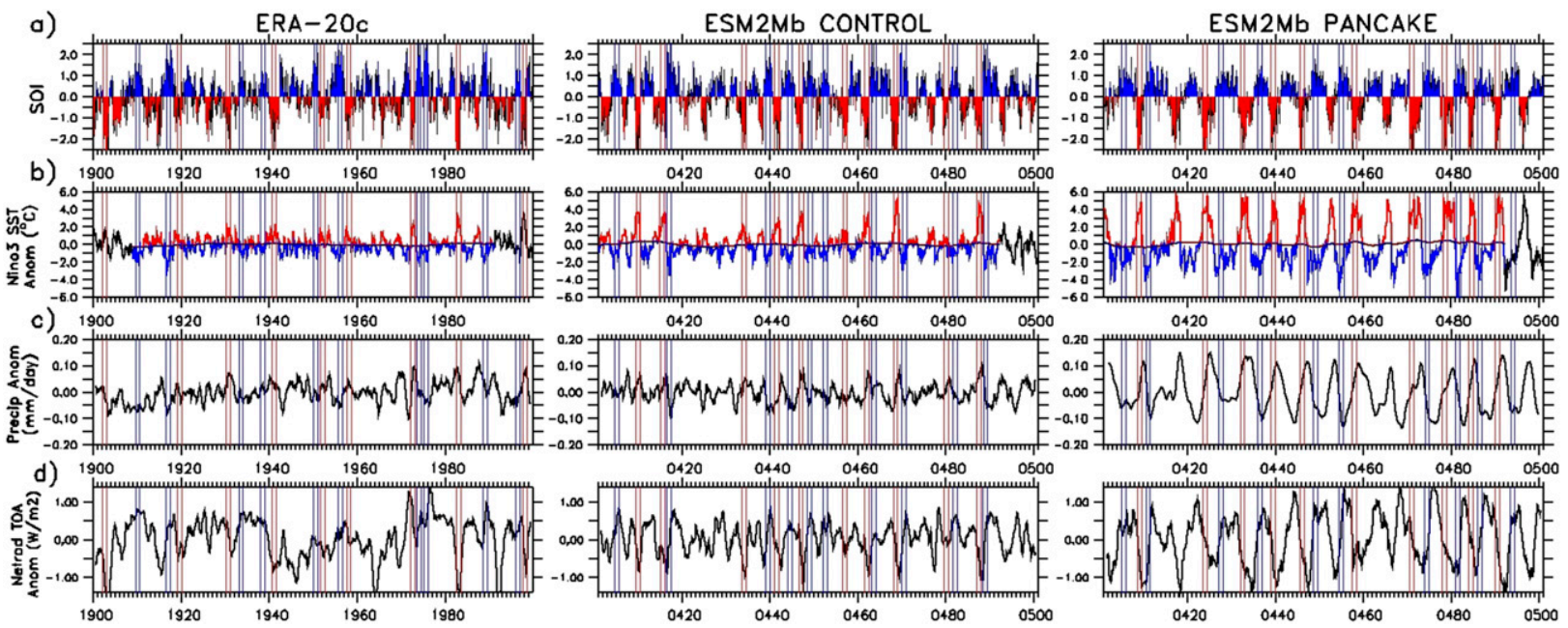

FIG. 5. (a) SOI, (b) Niño-3 SST anomaly $\left({ }^{\circ} \mathrm{C}\right)$, (c) tropical precipitation anomaly ( $\mathrm{mm} \mathrm{day}^{-1}$; averaged over $\left.20^{\circ} \mathrm{S}-20^{\circ} \mathrm{N}\right)$, and $(\mathrm{d})$ global net radiation at the top-of-the-atmosphere anomaly $\left(\mathrm{W} \mathrm{m}^{-2}\right.$; positive values correspond to downward flux) from (left) ERA-20C, (center) ESM2Mb CONTROL, and (right) ESM2Mb PANCAKE. The SOI is calculated from the SLP difference between Darwin (12 $\left.2^{\circ}, 130^{\circ} \mathrm{E}\right)$ and Tahiti $\left(17^{\circ} \mathrm{S}, 150^{\circ} \mathrm{W}\right)$. Sea surface temperature anomalies are monthly anomalies from the Niño- 3 region $\left(5^{\circ} \mathrm{S}-5^{\circ} \mathrm{N}, 150^{\circ}-90^{\circ} \mathrm{W}\right)$ calculated using a running 211-month triangular smoother. Blue colors indicate La Niña years, and red colors indicate El Niño years. The 10 El Niño and 10 La Niña years that were chosen for analysis in this paper are bracketed by vertical lines in their corresponding colors. The vertical scale is the same for in all panels. Tropical precipitation is the zonal average from $20^{\circ} \mathrm{S}$ to $20^{\circ} \mathrm{N}$. Abscissa shows the calendar year (for ERA-20C) or the model years.

Continent but are unchanged or warmer in the vicinity of the continent, whereas precipitation and $\omega$ decrease throughout this entire area. Precipitation and $\omega$ increase over a large region of the central equatorial Pacific, between $180^{\circ}$ and $100^{\circ} \mathrm{W}$, whereas SSTs decrease throughout that region.

The broad cooling of tropical SSTs in the equatorial region must be due to ocean dynamics because there is an increase in net heating at the ocean surface, especially in the western Pacific and eastern Indian basins (Fig. 2a). An increase in nitrate in the surface waters (Fig. 2h) suggests an increase in upwelling, as nitrate is concentrated in deeper water. This increased mixing is consistent with increased easterly wind stress near the equator (especially off the west coast of Africa and South America).

Some of the largest changes in SST occur near upwelling regions associated with meridional surface winds. For example, PANCAKE's SSTs in the Peru Current off the west coast of South America are approximately $5^{\circ} \mathrm{C}$ cooler than in CONTROL (Fig. 1). This suggests that the coarse representation of the Andes in our CONTROL simulations, which impact atmospheric subsidence in the region of the Peru Current, may not be the sole cause of the warm bias in the Peru Current (Wittenberg et al. 2006). The net surface heating in most of this region is greater in PANCAKE than in CONTROL (Fig. 2a), and although the winds are more zonal in PANCAKE, the wind speed is approximately $2 \mathrm{~m} \mathrm{~s}^{-1}$ stronger (Fig. $2 \mathrm{~g}$ ) and the coastal meridional winds are stronger, leading to increased upwelling along the Peruvian coast (Fig. 2h).

Just west of the coastal Peru Current, SSTs warm significantly over large portions of the eastern subtropical Pacific (Fig. 1). Throughout most of this region there is a decrease of low clouds (Fig. 2f) that reflect shortwave radiation (Fig. 2b) and an increase in high clouds (Fig. 2e) that trap outgoing longwave radiation (Fig. 2d). These changes are consistent with previous studies that have shown that orography leads to stronger descent in subtropical anticyclones and suppressed deep convection (Rodwell and Hoskins 2001), and removing the Andes, in particular, leads to warmer SSTs in the southern subtropical eastern Pacific as a result of cloud, evaporation, and SST feedbacks (e.g., Takahashi and Battisti 2007a,b; Feng and Poulsen 2014).

The large-scale zonally asymmetric Walker circulation can be depicted as the average of $\omega$ over the equatorial tropics $\left(5^{\circ} \mathrm{S}-5^{\circ} \mathrm{N}\right)$ in longitudinal-height space (Fig. 3a). The Walker circulation in the ERA-Interim data (Dee et al. 2011) from 1981-2010 (Fig. 3b) shows that the maximum velocities in the "up" direction (negative $\omega$ values) occur in the region of the Maritime Continent, including the warm pool of the western Pacific and eastern Indian Oceans, with significant upward motion over the longitudes of the Amazon rain forest. Air tends to descend over the eastern Pacific and Atlantic basins and over East Africa. This overall pattern and the zonal variation in $\omega$ are reproduced by the CONTROL 

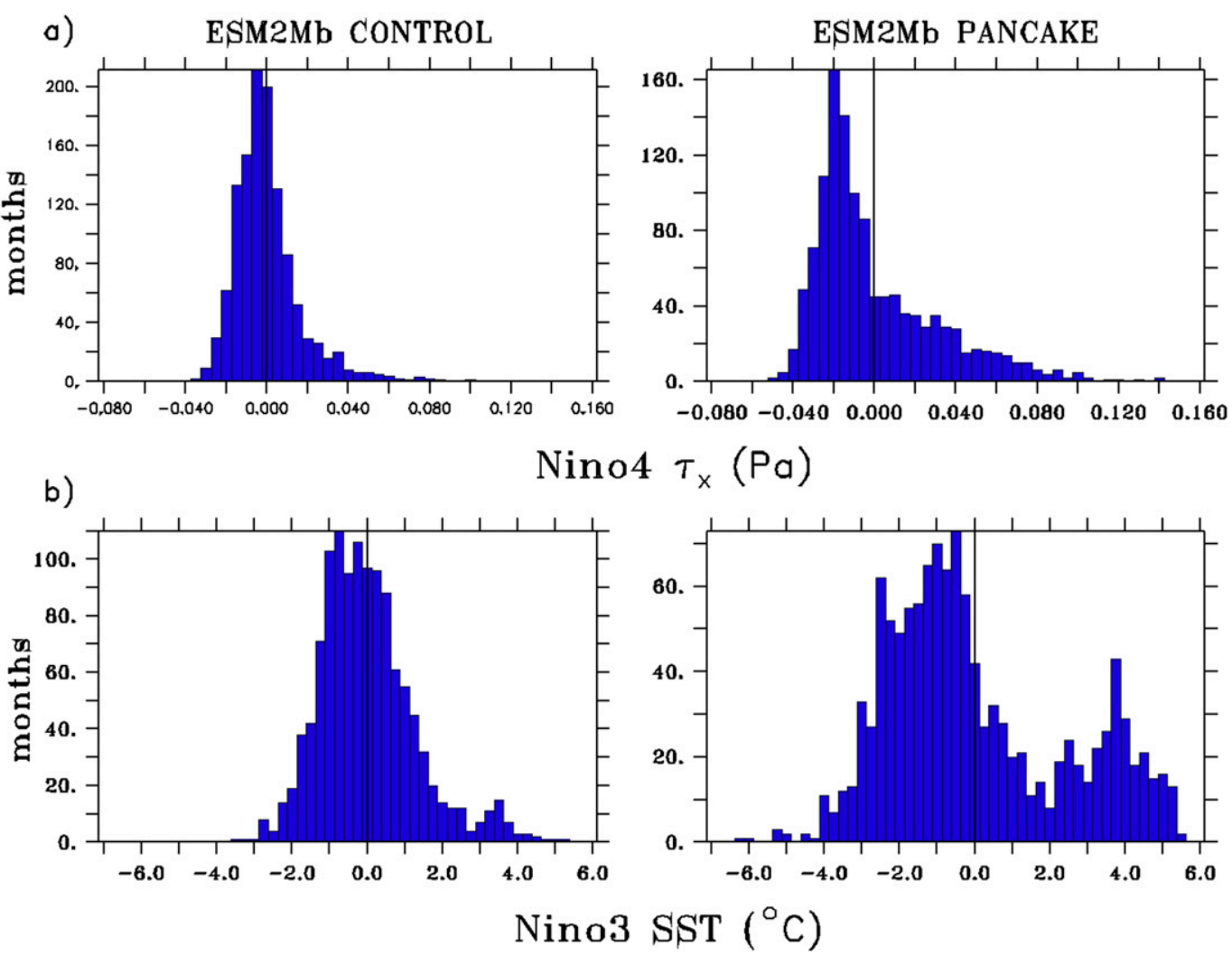

FIG. 6. Distribution of monthly (a) oceanic zonal wind stress anomalies in the Niño-4 region $\left(5^{\circ} \mathrm{S}-5^{\circ} \mathrm{N}\right.$, $\left.160^{\circ} \mathrm{E}-150^{\circ} \mathrm{W}\right)$ and (b) SST anomalies in the Niño-3 region $\left(5^{\circ} \mathrm{S}-5^{\circ} \mathrm{N}, 150^{\circ}-90^{\circ} \mathrm{W}\right)$ for (left) ESM2Mb CONTROL and (right) ESM2Mb PANCAKE, model years 401-500. The zero-anomaly line is shown. Note the difference in scale of the $y$ axis between CONTROL and PANCAKE panels.

experiments (Fig. 3). Biases in the CONTROL simulation's Walker circulation include too-concentrated upward motion over the Maritime Continent, too little upward motion over the Amazon, and too much downward motion over the eastern Pacific. In PANCAKE (Fig. 3d), the zonal variation in $\omega$ is remarkably dampened. Although air tends to descend over the Atlantic region with the same intensity as in CONTROL, and the weak $\omega$ in the middle of the troposphere over the central Pacific in CONTROL does not change much, the rest of the tropics have substantially reduced upward and downward vertical motions throughout the atmosphere.

Various metrics have been used as a measure of the overall strength of the time-mean Walker circulation, including the difference in sea level pressure between the equatorial western and eastern Pacific (dSLP) (Walker and Bliss 1932; Vecchi et al. 2006; Vecchi and Soden 2007), the maximum values of mass streamfunctions (Trenberth et al. 2000), and deviations from the zonal mean of $\omega$ in the middle of the tropical troposphere (Burls and Fedorov 2014). Each of these metrics calculated for the PANCAKE experiments exhibit a weakening of the
Walker circulation in the range of $31 \%-60 \%$ (Table $\mathrm{S} 1$ in the supplemental material), with a mean value of $43 \%$ (ESM2Mb) and 45\% (ESM2G). The weakening of the Pacific Walker circulation when mountains are removed is consistent with a previous study that examined the role of orography in the tropical Indian and Pacific Oceans during boreal summer (Abe et al. 2004).

In addition to the overall weakening of the Walker circulation, the structure of the circulation is changed in the PANCAKE experiments. Air almost ceases to descend throughout most of the atmosphere over the western Indian Ocean and East Africa in the PANCAKE experiments $\left(\sim 35^{\circ}-55^{\circ} \mathrm{E}\right)$, disrupting the Indian Ocean branch of the Walker cell. The upward branch of the Walker circulation in PANCAKE is not focused over the Pacific warm pool; it extends over the entire Indian Ocean.

The weakening of the Walker circulation in these experiments occurs without significant weakening of the Hadley circulation, which describes the zonally symmetric component of tropical convection. The Hadley circulation can be depicted as the zonal average of $\omega$ over the tropics $\left(30^{\circ} \mathrm{S}-30^{\circ} \mathrm{N}\right)$ in latitudinal-height 

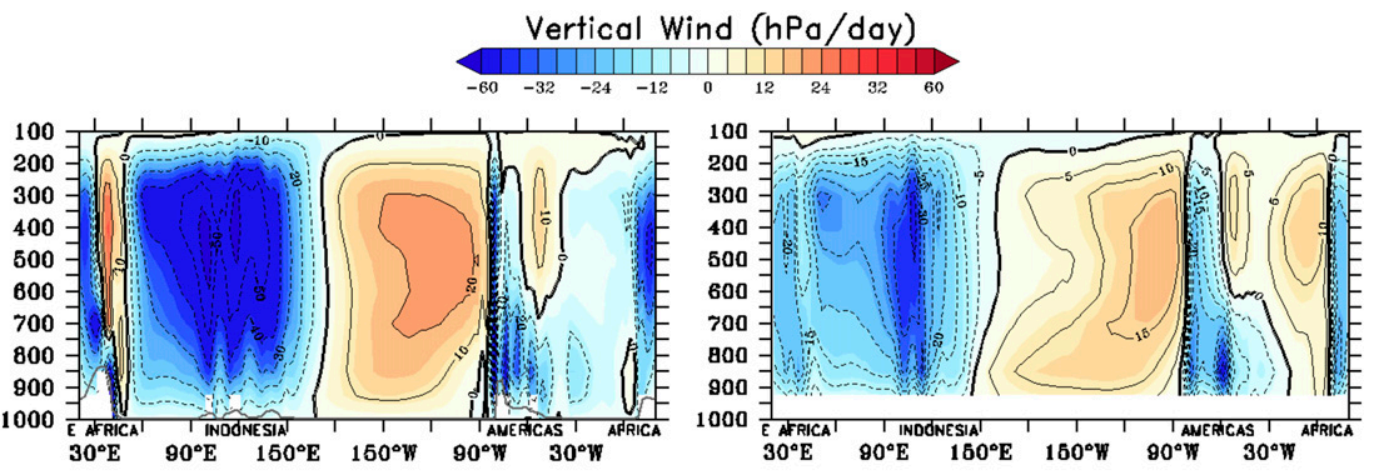

\section{ESM2Mb CONTROL}
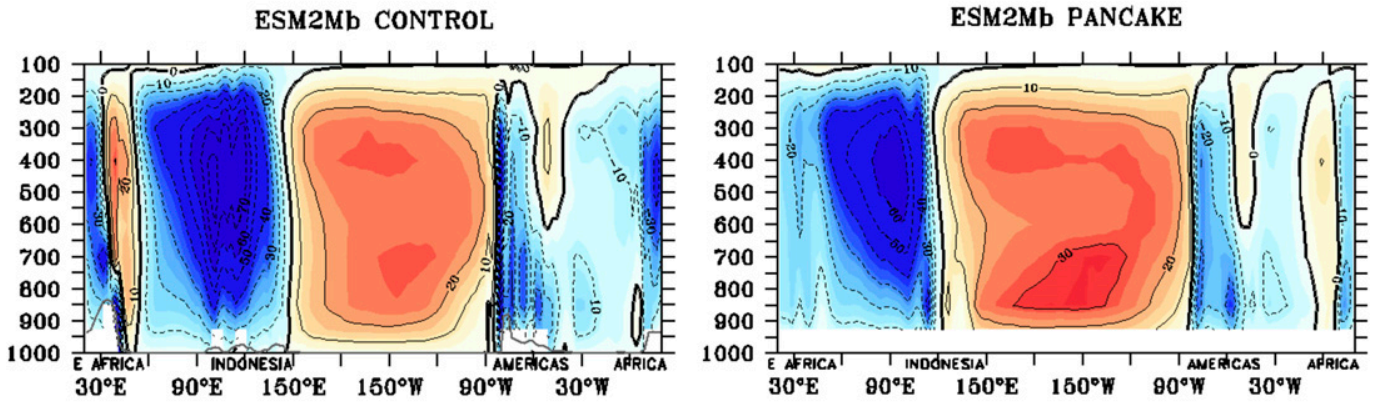

ESM2Mb CONTROL La Nina

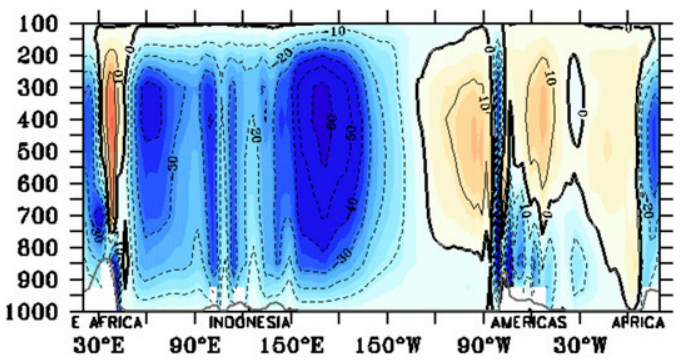

ESM2Mb CONTROL El Nino

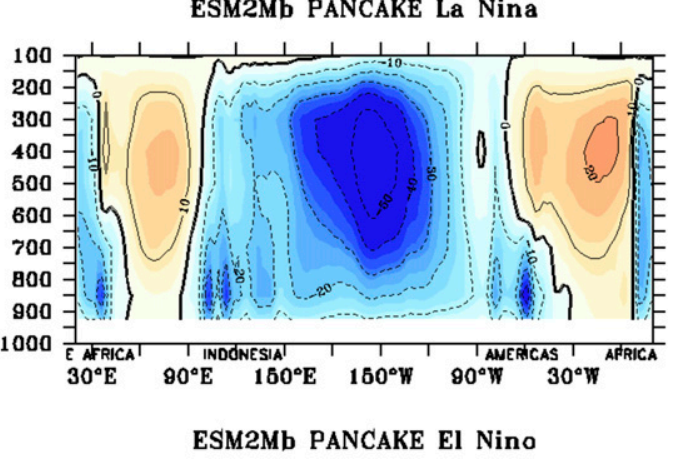

FIG. 7. Average vertical wind velocities $\left(\mathrm{hPa}\right.$ day ${ }^{-1}$ ) between $5^{\circ} \mathrm{N}$ and $5^{\circ} \mathrm{S}$ for (top) model years $401-500$, (middle) the 10 La Niña, and (bottom) the $10 \mathrm{El}$ Niño from (left) ESM2Mb CONTROL and (right) ESM2Mb PANCAKE. Spatial changes to the equatorial Walker circulation on interannual time scales in the PANCAKE simulations are partially responsible for the weakening of the circulation in the time mean. Blue color indicates rising motion; red color indicates subsidence.

space (Fig. 3). In ERA-Interim data from 1981-2010 (Fig. 3b), the average Hadley circulation is shown to be dominated by air rising in the Northern Hemisphere, consistent with the fact that the ITCZ spends more time each year in the Northern Hemisphere. In the PANCAKE experiment, the large-scale $\omega$ pattern is even more symmetric around the equator, consistent with the changes in the ITCZ discussed above. This results in a sharper division between the equatorial region of low $\omega$ and the regions centered at about $7^{\circ} \mathrm{N}$ and $7^{\circ} \mathrm{S}$ of the equator of high $\omega$, consistent with diminished rains over the equator Maritime Continent and cooler equatorial SSTs. The overall variation in the magnitude of average $\omega$ across different latitudes remains largely unchanged in PANCAKE, as does the overall width and height of the tropics. Based on the fractional change to the maximum value of the zonally averaged overturning streamfunction between $30^{\circ} \mathrm{S}-30^{\circ} \mathrm{N}$, the strength of the Hadley circulation changes are small in the ESM2Mb and ESM2G PANCAKE experiments $(-1.93 \%$ in ESM2Mb and $0.97 \%$ in ESM2G).

\section{Interannual variability}

Although the preindustrial CONTROL simulations of the two models used in this study exhibit ENSOs with 


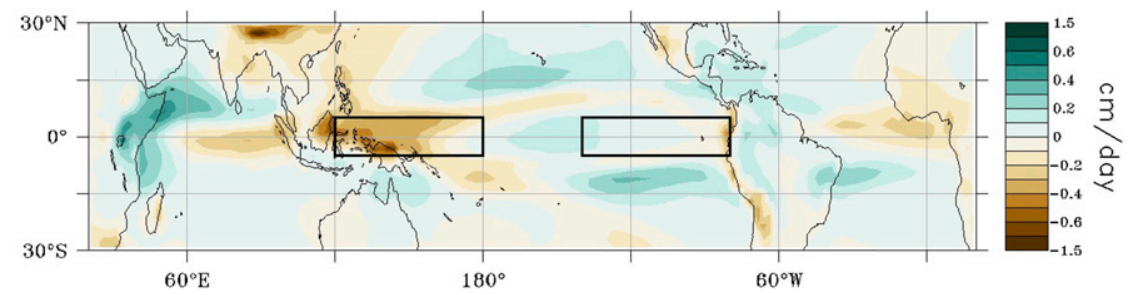

ESM2Mb Precip Pancake minus Control Years 401-500
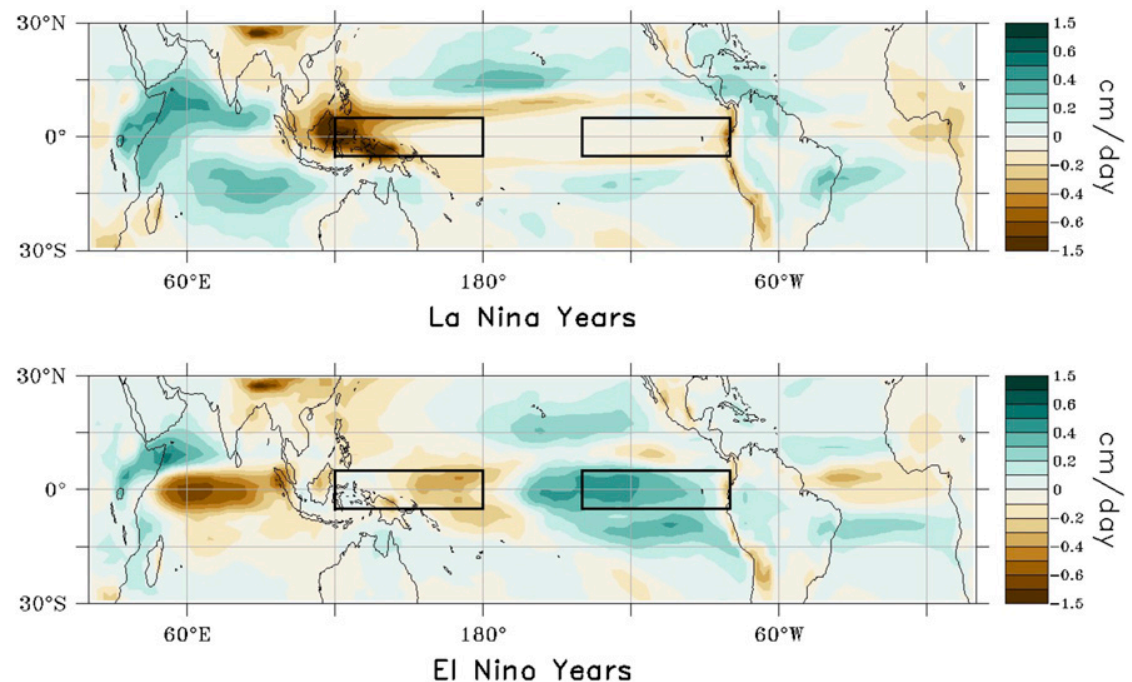

FIG. 8. Precipitation difference (ESM2Mb PANCAKE minus CONTROL) for (top) the model years 401-500, (middle) the 10 La Niña years, and (bottom) the 10 El Niño years.

different characteristics, with ESM2Mb's ENSO exhibiting larger eastern Pacific SST anomalies and ESM2G's ENSO exhibiting smaller anomalies than observations (Kim and Yu 2012; Bellenger et al. 2014), ENSO in both models changes in the same qualitative manner when mountains are removed. Without orography, ENSO becomes stronger and more skewed toward warm events, and the interval between events becomes more regular (Fig. 4). The ENSO period, calculated from model years $101-500$, increases from 3.7 to $5.7 \mathrm{yr}$ in ESM2Mb and from 2.8 to $4.5 \mathrm{yr}$ in ESM2G. The semiannual cycle in the Niño- 3 region $\left(5^{\circ} \mathrm{S}-5^{\circ} \mathrm{N}, 150^{\circ}-90^{\circ} \mathrm{W}\right)$ is stronger in PANCAKE, especially in ESM2G, consistent with the increased meridional symmetry about the equator (see the Hadley circulation in Fig. 3d). Interannual variation in anomalies of equatorial SSTs (Fig. 4), wind stress, and precipitation in the Pacific and Indian basins increases in PANCAKE relative to CONTROL. In CONTROL and in observations, these patterns of interannual anomalies span the Pacific basin in some years but only reach the central Pacific in other years (Fig. 4). In PANCAKE, they consistently extend across the entire Pacific basin (Fig. 4), lengthening the period. As suggested by previous authors (Watanabe and Wittenberg 2012;
Watanabe et al. 2012), the increased strength of ENSO has a large impact on the total tropical precipitation (Fig. 5c) and also the global net radiation at the top of the atmosphere (Fig. 5d).

Because these models share the same atmospheric component, similar experiments could be carried out with other fully coupled AOGCMs in order to test the robustness of this response. However, the qualitative consistency of the results between our two ESMs and a previous study (Kitoh 2007) is encouraging.

The response of ENSO when orography is removed from these models is so strong that ENSO events have a much more significant influence on the mean climate in PANCAKE than they do in CONTROL. For example, in the CONTROL runs, as in nature, the distribution of monthly wind stress and SST anomalies over the Niño-4 $\left(5^{\circ} \mathrm{S}-5^{\circ} \mathrm{N}, 160^{\circ} \mathrm{E}-150^{\circ} \mathrm{W}\right)$ and Niño-3 $\left(5^{\circ} \mathrm{S}-5^{\circ} \mathrm{N}\right.$, $150^{\circ}-90^{\circ} \mathrm{W}$ ) regions is nearly normal, and the mode coincides with the mean (Fig. 6). Most months show no anomaly in these values, so the distribution peaks at the zero-anomaly (mean) line, and there is a very small tail with positive (westerly) wind stress values and SSTs from ENSO warm events. In the PANCAKE simulations these distributions are different. The mode and 

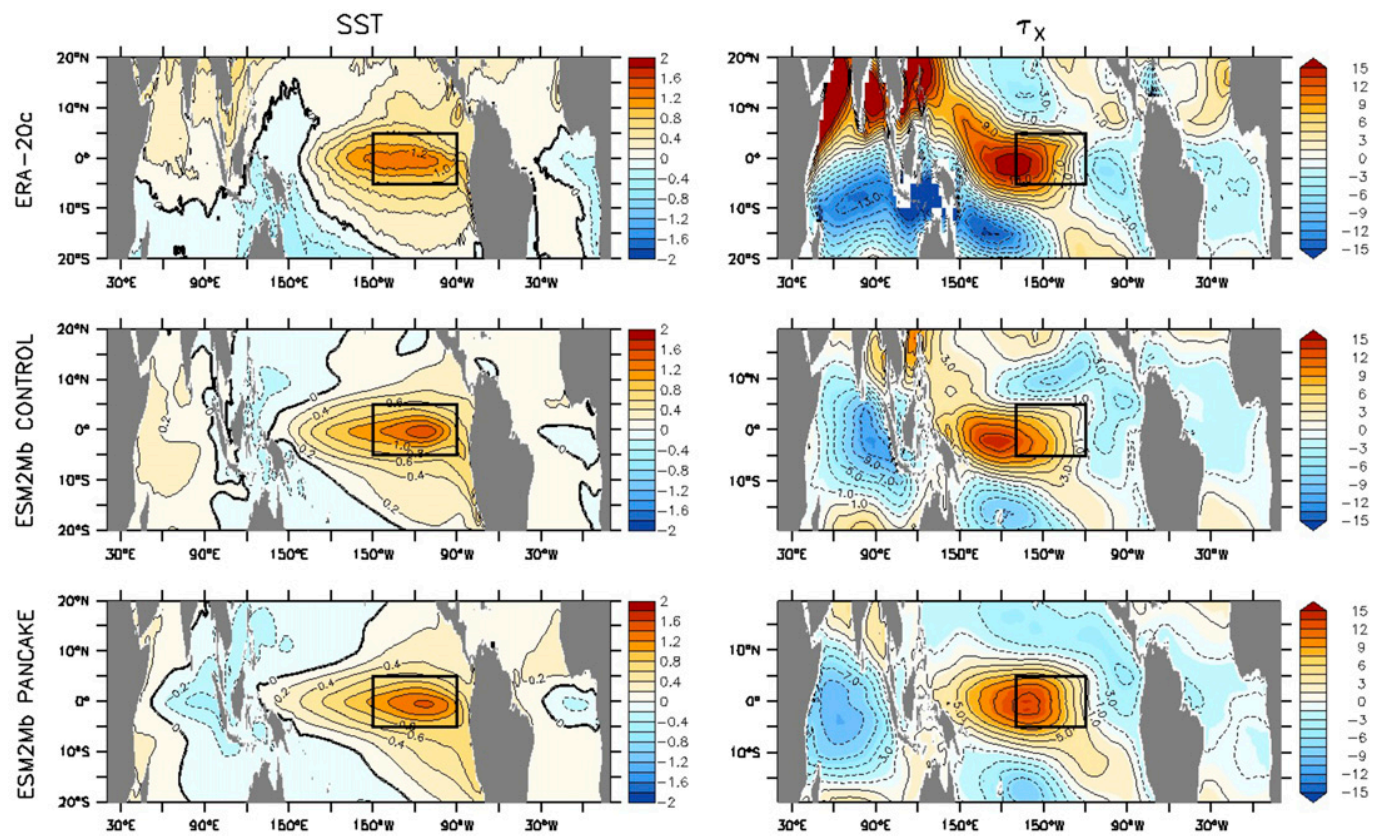

FIG. 9. (left) SST $\left({ }^{\circ} \mathrm{C}\right)$ and (right) zonal wind stress over the ocean $(\mathrm{kPa})$ regressed on Niño-3 region $\left(5^{\circ} \mathrm{S}-5^{\circ} \mathrm{N}, 150^{\circ}-\right.$ $90^{\circ} \mathrm{W}$ ) SST anomalies for (top) ERA-20C, (middle) ESM2Mb CONTROL, and (bottom) ESM2Mb PANCAKE. The SST regressions in (left) have a box over the Niño-3 region, and the zonal wind stress regressions in (right) have a box over the Niño-3.4 region.

the mean no longer coincide; the mean is in-between $\mathrm{La}$ Niña and El Niño values (Figs. 6). Because changes to ENSO are often diagnosed through analysis of the mean climate, the strong impact of ENSO on the mean climate in the experiments complicates the interpretation of the results.

To distinguish aspects of the changes to the mean tropical circulation that are related to ENSO versus those that are not, we compare the mean climate and circulation patterns from $10 \mathrm{El}$ Niño years and $10 \mathrm{La}$ Niña years in CONTROL and PANCAKE. Using time series from model years 401-500, we picked spans of 12 consecutive months using the Southern Oscillation index (SOI) and Niño-3 SST anomalies to represent El Niño and La Niña years and repeated this process with the ERA-20C (Fig. 5).

PANCAKE's much stronger ENSO is apparent when comparing La Niña and El Niño years with CONTROL (Fig. 7). In both ESM2Mb and ESM2G, the PANCAKE La Niña and El Niño years exhibit vertical velocities of similar magnitudes to CONTROL; however, the spatial pattern of upward and downward movement is different. During La Niña years, the region of descending air (red color in Fig. 7, middle) over the central and eastern Pacific extends about $20^{\circ}$ farther west in PANCAKE; air descends over the eastern part of Indonesia. The descending air that is over East Africa in CONTROL also shifts west and is over West Africa and the eastern
Atlantic in PANCAKE. During El Niño years, the large region of rising air over the Pacific (blue color in Fig. 7, bottom) shifts farther east, consistent with the increased longitudinal span of the anomalies shown in Fig. 4. Air descends over most of the Indian Ocean, but not East Africa, and there is less rain over Indonesia. Although the equatorial circulation strength does not change much between CONTROL and PANCAKE during La Niña and El Niño years, the shifts in patterns of rising and falling air cause the circulations to largely cancel each other out in the time mean (Fig. 7, top).

Because of the stronger ENSO in PANCAKE relative to CONTROL, interannual variation in tropical precipitation over the eastern equatorial Pacific is stronger as well (Fig. 8). La Niña years are drier in PANCAKE than CONTROL (Fig. 8, middle; see the box over eastern equatorial Pacific), El Niño years are wetter (Fig. 8, bottom), and the mean changes are more subdued (Fig. 8, top). However, the western equatorial Pacific is drier in both $\mathrm{La}$ Niña and El Niño years (see the box over the western equatorial Pacific), and East Africa is wetter, consistent with the changes to the Walker circulation discussed above.

What are the main drivers of the changes to ENSO in PANCAKE Earth? The increased amplitude and period of PANCAKE's ENSO is partially explained by the eastward shift in wind stress anomalies regressed onto the Niño-3 region SST anomalies (Fig. 9), as the eastward 
a)

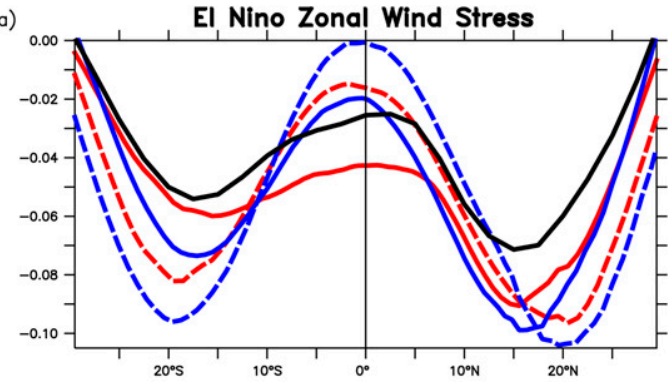

c)

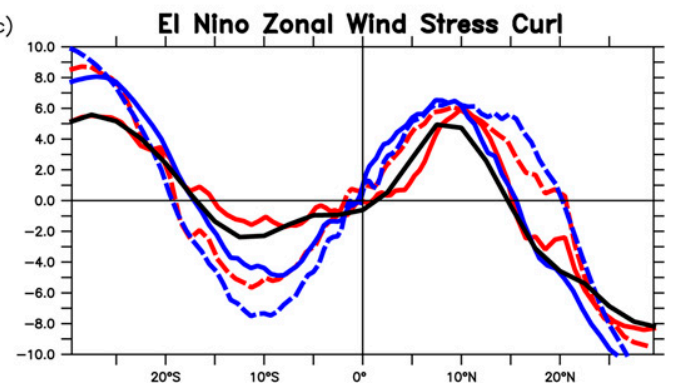

b)

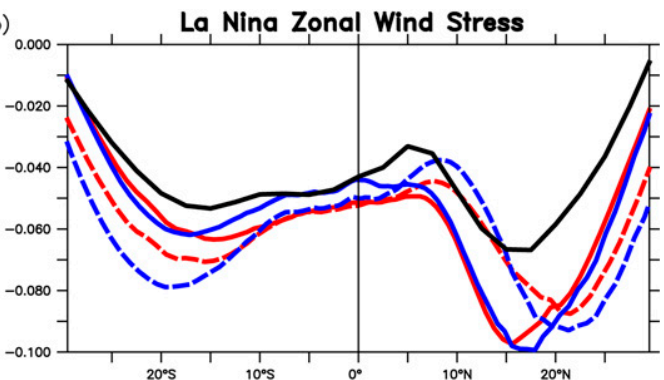

d)

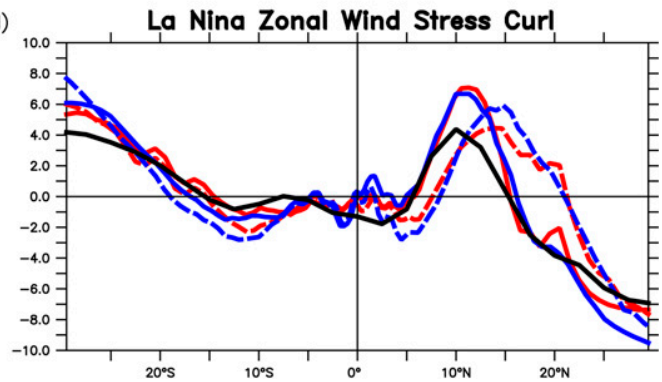

FIG. 10. (a),(b) Zonal wind stress (Pa) and (c),(d) zonal wind stress curl $\left(\mathrm{N} \mathrm{m}^{-3}\right)$ averaged over the Pacific Ocean $\left(150^{\circ} \mathrm{E}-90^{\circ} \mathrm{W}\right)$ during (a),(c) El Niño years and (b),(d) La Niña years. Lines represent ERA-20C (black), ESM2Mb CONTROL (solid blue), ESM2Mb PANCAKE (dashed blue), ESM2G CONTROL (solid red), and ESM2G PANCAKE (dashed red). All model years are 401-500. Positive wind stress is westerly. Wind stress curl is scaled by $10^{8}$. Positive wind stress curl is associated with northward Sverdrup transport in both hemispheres.

shifted anomalies enhance atmosphere-ocean feedbacks in the eastern equatorial Pacific where the thermocline is close to the surface and require the off-equatorial oceanic Rossby waves to travel a greater distance before they are reflected back as equatorial Kelvin waves (Wittenberg et al. 2006; Capotondi et al. 2006, and references therein). This shift in wind anomalies regressed onto Niño-3 SST anomalies results in both a stronger coupling between Niño-3 SST anomalies and Niño-3.4 wind stress anomalies (increases of 3.1 and $2.6 \mathrm{~Pa}^{\circ} \mathrm{C}^{-1}$ in ESM2Mb and ESM2G, respectively, corresponding to fractional changes of $54 \%$ and $61 \%$ ) and a weaker delayed negative feedback from reflected Kelvin waves, which are both consistent with the increased strength of El Niño events.

Changes to PANCAKE's tropical wind field also have a strong influence on ENSO dynamics. PANCAKE's equatorial wind zone, between the latitudes of each hemisphere's strongest easterly winds, is wider than CONTROL's (Figs. 10a,b). The wider equatorial wind zone in PANCAKE impacts the off-equatorial wind stress curl field that drives the Sverdrup transport responsible for interannual changes in the zonal mean depth of the equatorial thermocline and the discharge (recharge) of heat from the equatorial thermocline during El Niño (La Niña) events (Figs. 10c,d; positive wind stress curl corresponds to northward Sverdrup transport in both hemispheres). PANCAKE's Sverdrup transport of heat away from the equator is much greater during El Niño.
During La Niña, PANCAKE has more Sverdrup convergence just north of the equator, consistent with the recharging of the equatorial thermocline's heat content.

The very strong ENSO events are associated with a strong flattening of the equatorial Pacific thermocline (Fig. 11, bottom). The steep La Niña thermocline (Fig. 11, middle), associated with stronger equatorial easterly wind stress in PANCAKE La Niña years (Fig. 10b), allows more heat to build up in the western Pacific warm pool to later discharge during an El Niño event (Jin 1997), contributing to the stronger ENSO warm events in the PANCAKE simulations (e.g., Fedorov and Philander 2001; Wittenberg 2002; Zelle et al. 2005; Vecchi and Wittenberg 2010). The large El Niño events lead to the skew toward stronger warm events mentioned above because the increase in strength of the La Niña events is limited by how dry the central Pacific equatorial atmosphere can get. As with the Pacific Ocean, the much stronger changes in the slope of the Indian Ocean equatorial thermocline between PANCAKE La Niña and El Niño years relative to CONTROL is consistent with the much greater interannual variation in SST (Fig. 5), wind stress anomalies, and precipitation anomalies in both basins.

\section{Discussion}

When mountains are present, tropical convection is focused in the Maritime Continent region, and SST 


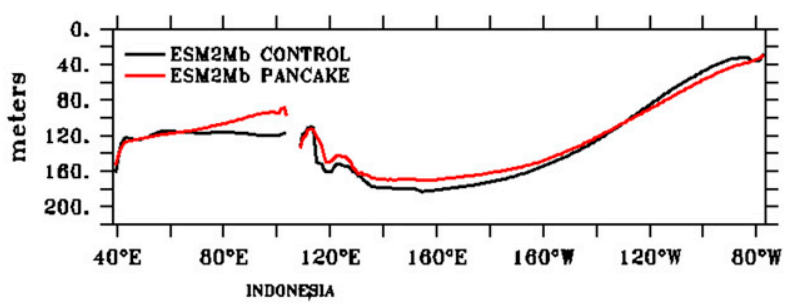

Mean Thermocline

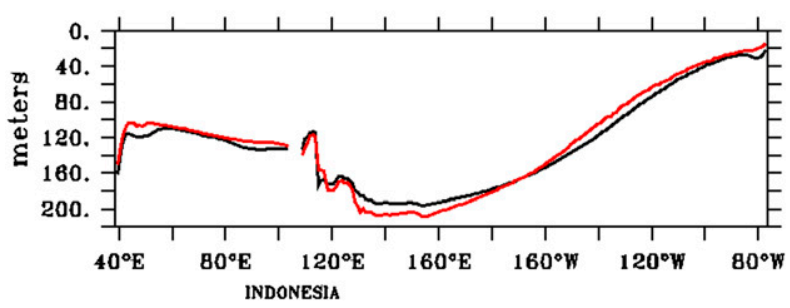

La Nina Thermocline

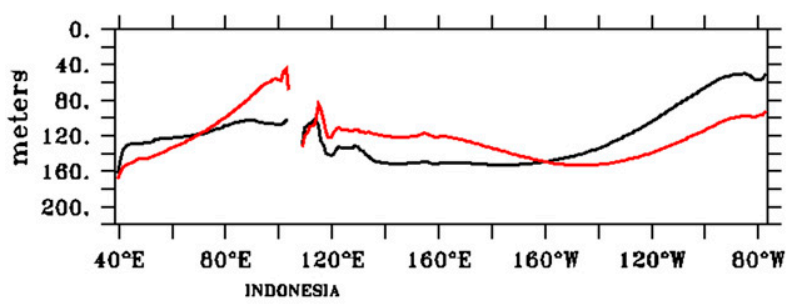

El Nino Thermocline

FIG. 11. Average depth $\left(\mathrm{m} ; 5^{\circ} \mathrm{S}-5^{\circ} \mathrm{N}\right)$ of the $20^{\circ}$ isotherm in the equatorial Indian and Pacific basins. The 100-yr mean from (top) model years 401-500, (middle) the 10 La Niña years, and (bottom) the $10 \mathrm{El}$ Niño years for CONTROL (black) and ESM2Mb PANCAKE (red). Approximate location of Indonesia is indicated below the abscissa.

anomalies related to ENSO often only reach the central Pacific, whereas without mountains the Maritime Continent region dries and ENSO warm SST anomalies consistently cross the entire Pacific basin (Fig. 4). This suggests that Maritime Continent orography might have a mooring effect on convection. Previous studies have highlighted two distinct mechanisms by which tropical orography influences monsoonal circulation by promoting convection: 1 ) mountains provide elevated heating surfaces and 2) mountains provide "lift" by forcing air upslope (Meehl 1992; Kutzbach et al. 1993; Rodwell and Hoskins 2001). In each case, convection leads to precipitation and the release of latent heat into the atmosphere, further fueling the convection. Although these authors stressed the importance of these mechanisms in monsoon systems, these mechanisms should also operate over the Maritime Continent. The raised heated surfaces and orographic lift associated with Maritime Continent orography may play an important role in mooring convection over that region.
Apart from Maritime Continent orography, the Himalayas and the Andes may play important roles in the changes found in these experiments. The presence of the Himalayas strengthens monsoonal winds over the Indian Ocean; when they are not present, winds are more zonal over the Indian Ocean, and the Indian Ocean thermocline exhibits much greater interannual variation (Fig. 9), possibly contributing to the changes in tropical rainfall in the PANCAKE experiments. In a recent study, the height of the Andes was varied in simulations using the National Center for Atmospheric Research Community Climate System Model, version 4 (Feng and Poulsen 2014). Lowering of the Andes lead to a decrease of approximately $22 \%$ in the Walker circulation compared with the control Andes topography. The authors attributed this change to a $0.8^{\circ} \mathrm{C}$ decrease in the equatorial Pacific SST gradient when the Andes were lowered, associated with decreased low cloud formation and increased SSTs over the southeastern Pacific basin. In our experiment, removing orography had similar effects in the southeastern Pacific basin, but the equatorial Pacific SST gradient did not decrease as much $\left(0.5^{\circ} \mathrm{C}\right.$ in $\mathrm{ESM} 2 \mathrm{Mb}$ and $0.3^{\circ} \mathrm{C}$ in ESM2G), and the Walker decreased by about twice as much.

Orography associated with the East African rift system is also likely responsible for some of the changes in tropical climate in our PANCAKE circulation (Sepulchre et al. 2006). Additional studies are required to examine the role of different orography in tropical climate. This study highlights the possible role of Maritime Continent orography in impacting the large-scale tropical circulation and tropical precipitation patterns.

\section{Conclusions}

We performed a classic idealized experiment using state-of-the-art Earth system models to explore the impact of mountains on Earth's climate system. Our simulations exhibited similar characteristics to previous studies, including more zonal winds and weaker monsoons when land surface topography is removed. However, we also found broad changes to tropical circulation patterns, impacting the mean climate and interannual variability. Without orography, convection and precipitation over the Maritime Continent weaken, and convection over East Africa increases significantly. Changes in convection and surface winds due to the removal of mountains have a strong influence on equatorial atmosphere-ocean dynamics, leading to a more regular ENSO with a lower frequency and much stronger amplitude. The large changes to ENSO result in a mean Pacific Walker circulation that is approximately $44 \%$ weaker and much larger interannual variation in tropical precipitation and global net radiation at the top 
of the atmosphere. These results are consistent across the two models used in this study and are qualitatively similar to the results of a previous study that used a nonrelated AOGCM (Kitoh 2007).

The results of this study are especially interesting because they suggest that atmospheric-driven changeschanges in the surface winds induced by changes in land surface elevation - can have a significant impact on the equatorial ocean dynamics, which play an important role in ENSO dynamics and climate variability around the globe.

How have changes to Earth's orography over the last few million years influenced ENSO and the Walker circulation, and what were the impacts on East African, tropical, and global climate? Although we speculate that changes in Maritime Continent orography may have had a strong influence on climate dynamics over the last few million years, our study cannot constrain the role of specific orography in the changes we found and did not attempt to examine a realistic paleo-orographic scenario. Future work should address the influence of particular orography, especially in the area of the western Pacific warm pool, on ENSO, the Walker circulation, and regional to global climate.

Acknowledgments. This work was supported in part by the National Science Foundation (NSF) Frontiers in Earth System Dynamics and NSF Grant EAR-1338553. We thank Jane Baldwin, John P. Dunne, Isaac Held, Jason Kirk, Jay Quade, J. Robert Toggweiler, Michael Winton, and Jianjun Yin for comments on this paper.

\section{REFERENCES}

Abe, M., T. Yasunari, and A. Kitoh, 2004: Effects of large-scale orography on the coupled atmosphere-ocean system in the tropical Indian and Pacific Oceans in boreal summer. J. Meteor. Soc. Japan, 82, 745-759.

Barron, E. J., 1985: Explanations of the Tertiary global cooling trend. Palaeogeogr. Palaeoclimatol. Palaeoecol., 50, 45-61, doi:10.1016/S0031-0182(85)80005-5.

— explaining paleoclimates: Results from Cretaceous climate model sensitivity studies. J. Geophys. Res., 89, 1267-1279, doi:10.1029/JD089iD01p01267.

Bellenger, H., E. Guilyardi, J. Leloup, M. Lengaigne, and J. Vialard, 2014: ENSO representation in climate models: From CMIP3 to CMIP5. Climate Dyn., 42, 1999-2018, doi:10.1007/s00382-013-1783-z.

Bischoff, T., and T. Schneider, 2016: The equatorial energy balance, ITCZ position, and double-ITCZ bifurcations. J. Climate, 29, 2997-3013, doi:10.1175/JCLI-D-15-0328.1.

Boos, W. R., and Z. Kuang, 2010: Dominant control of the South Asian monsoon by orographic insulation versus plateau heating. Nature, 463, 218-222, doi:10.1038/nature08707.

Brierley, C. M., and A. V. Fedorov, 2010: Relative importance of meridional and zonal sea surface temperature gradients for the onset of the ice ages and Pliocene-Pleistocene climate evolution. Paleoceanography, 25, PA2214, doi:10.1029/ 2009PA001809.

Broccoli, A. J., K. A. Dahl, and R. J. Stouffer, 2006: Response of the ITCZ to Northern Hemisphere cooling. Geophys. Res. Lett., 33, L01702, doi:10.1029/2005GL024546.

Burls, N. J., and V. Fedorov, 2014: What controls the mean eastwest sea surface temperature gradient in the equatorial $\mathrm{Pa}$ cific: The role of cloud albedo. J. Climate, 27, 2757-2778, doi:10.1175/JCLI-D-13-00255.1.

Capotondi, A., A. Wittenberg, and S. Masina, 2006: Spatial and temporal structure of Tropical Pacific interannual variability in 20th century coupled simulations. Ocean Modell., 15, 274298, doi:10.1016/j.ocemod.2006.02.004.

Compo, G. P., and Coauthors, 2011: The Twentieth Century Reanalysis project. Quart. J. Roy. Meteor. Soc., 137, 1-28, doi:10.1002/qj.776.

Dai, A., 2006: Precipitation characteristics in eighteen coupled climate models. J. Climate, 19, 4605-4630, doi:10.1175/JCLI3884.1.

Dee, D. P., and Coauthors, 2011: The ERA-Interim reanalysis: Configuration and performance of the data assimilation system. Quart. J. Roy. Meteor. Soc., 137, 553-597, doi:10.1002/qj.828.

Domínguez-Rodrigo, M., 2014: Is the "Savanna hypothesis" a dead concept for explaining the emergence of the earliest hominins? Curr. Anthropol., 55, 59-81, doi:10.1086/674530.

Donohoe, A., J. Marshall, D. Ferreira, and D. Mcgee, 2013: The relationship between ITCZ location and cross-equatorial atmospheric heat transport: From the seasonal cycle to the last glacial maximum. J. Climate, 26, 3597-3618, doi:10.1175/ JCLI-D-12-00467.1.

Dunne, J. P., and Coauthors, 2012: GFDL's ESM2 global coupled climate-carbon Earth System Models. Part I: Physical formulation and baseline simulation characteristics. J. Climate, 25, 6646-6665, doi:10.1175/JCLI-D-11-00560.1.

_ carbon Earth System Models. Part II: Carbon system formulation and baseline simulation characteristics. J. Climate, 26, 2247-2267, doi:10.1175/JCLI-D-12-00150.1.

Fedorov, A. V., and S. G. Philander, 2001: A stability analysis of tropical ocean-atmosphere interactions: Bridging measurements and theory for El Niño. J. Climate, 14, 3086-3101, doi:10.1175/1520-0442(2001)014<3086:ASAOTO>2.0.CO;2.

— P. S. Dekens, M. McCarthy, A. C. Ravelo, P. B. deMenocal, M. Barreiro, R. C. Pacanowski, and S. G. Philander, 2006: The Pliocene paradox (mechanisms for a permanent El Niño). Science, 312, 1485-1489, doi:10.1126/science.1122666.

_ C. M. Brierley, K. T. Lawrence, Z. Liu, P. S. Dekens, and A. C. Ravelo, 2013: Patterns and mechanisms of early Pliocene warmth. Nature, 496, 43-49, doi:10.1038/nature12003.

Feng, R., and C. J. Poulsen, 2014: Andean elevation control on tropical Pacific climate and ENSO. Paleoceanography, 29, 795-809, doi:10.1002/2014PA002640.

Frierson, D. M. W., and Coauthors, 2013: Contribution of ocean overturning circulation to tropical rainfall peak in the Northern Hemisphere. Nat. Geosci., 6, 940-944, doi:10.1038/ngeo1987.

Guilyardi, E., 2006: El Niño-mean state-seasonal cycle interactions in a multi-model ensemble. Climate Dyn., 26, 329348, doi:10.1007/s00382-005-0084-6.

H. Bellenger, M. Collins, S. Ferrett, W. Cai, and A. Wittenberg, 2012: A first look at ENSO in CMIP5. Clivar Exchanges, No. 17, International CLIVAR Project Office, Southampton, United Kingdom, 29-32. [Available online at 
http://www.uib.no/People/ngfhd/EarthClim/Publications/Papers/ Guilyardi_etal_2012.pdf.]

Hill, S. A., Y. Ming, and I. M. Held, 2015: Mechanisms of forced tropical meridional energy flux change. J. Climate, 28, 17251742, doi:10.1175/JCLI-D-14-00165.1.

Jin, F.-F., 1997: An equatorial ocean recharge paradigm for ENSO. Part II: A stripped-down coupled model. J. Atmos. Sci., 54, 830 847, doi:10.1175/1520-0469(1997)054<0830:AEORPF > 2.0.CO;2.

Kim, S. T., and J. Y. Yu, 2012: The two types of ENSO in CMIP5 models. Geophys. Res. Lett., 39, L11704, doi:10.1029/ 2012GL052006.

Kitoh, A., 1997: Mountain uplift and surface temperature changes. Geophys. Res. Lett., 24, 185-188, doi:10.1029/96GL03953.

_ 2002: Effects of large-scale mountains on surface climate. A coupled ocean-atmosphere general circulation model study. J. Meteor. Soc. Japan, 80, 1165-1181, doi:10.2151/jmsj.80.1165.

__, 2004: Effects of mountain uplift on East Asian summer climate investigated by a coupled atmosphere-ocean GCM. J. Climate, 17, 783-802, doi:10.1175/1520-0442(2004)017<0783: EOMUOE $>2.0 . \mathrm{CO} ; 2$.

_ 2007: ENSO modulation by mountain uplift. Climate Dyn., 28, 781-796, doi:10.1007/s00382-006-0209-6.

Kutzbach, J. E., P. J. Guetter, W. F. Ruddiman, and W. L. Prell, 1989: Sensitivity of climate to late Cenozoic uplift in southern Asia and the American west: Numerical experiments. J. Geophys. Res., 94, 18393-18 407, doi:10.1029/JD094iD15p18393.

- W. L. Prell, and W. F. Ruddiman, 1993: Sensitivity of Eurasian climate to surface uplift of the Tibetan Plateau. J. Geol., 101, 177-190.

Lee, J.-Y., B. Wang, K.-H. Seo, K.-J. Ha, A. Kitoh, and J. Liu, 2015: Effects of mountain uplift on global monsoon precipitation. Asia-Pacific J. Atmos. Sci., 51, 275-290, doi:10.1007/ s13143-015-0077-2.

Lin, J. L., and Coauthors, 2006: Tropical intraseasonal variability in 14 IPCC AR4 climate models. Part I: Convective signals. J. Climate, 19, 2665-2690, doi:10.1175/JCLI3735.1.

Manabe, S., and T. B. Terpstra, 1974: The effects of mountains on the general circulation of the atmosphere as identified by numerical experiments. J. Atmos. Sci., 31, 3-42, doi:10.1175/ 1520-0469(1974)031<0003:TEOMOT>2.0.CO;2.

— , and A. Broccoli, 1990: Mountains and arid climates of middle latitudes. Science, 12, 192-195, doi:10.1126/science.247.4939.192.

Maroon, E. A., D. M. W. Frierson, and D. S. Battisti, 2015: The tropical precipitation response to Andes topography and ocean heat fluxes in an aquaplanet model. J. Climate, 28, 381-398, doi:10.1175/JCLI-D-14-00188.1.

Mechoso, C. R., and Coauthors, 1995: The seasonal cycle over the tropical Pacific in coupled ocean-atmosphere general circulation models. Mon. Wea. Rev., 123, 2825-2838, doi:10.1175/ 1520-0493(1995)123<2825:TSCOTT>2.0.CO;2.

Meehl, G., 1992: Effect of tropical topography on global climate. Annu. Rev. Earth Planet. Sci., 20, 85-112, doi:10.1146 annurev.ea.20.050192.000505.

Philander, S., D. Gu, and D. Halpern, 1996: Why the ITCZ is mostly north of the equator. J. Climate, 9, 2958-2972, doi:10.1175/1520-0442(1996)009<2958:WTIIMN>2.0.CO;2.

Ravelo, A. C., D. H. Andreasen, M. Lyle, A. Olivarez Lyle, and M. W. Wara, 2004: Regional climate shifts caused by gradual global cooling in the Pliocene epoch. Nature, 429, 263-267, doi:10.1038/nature02567.

Rodwell, M., and B. Hoskins, 2001: Subtropical anticyclones and summer monsoons. J. Climate, 14, 3192-3211, doi:10.1175/ 1520-0442(2001)014<3192:SAASM >2.0.CO;2.
Ruddiman, W., and J. Kutzbach, 1989: Forcing of late Cenozoic Northern Hemisphere climate by plateau uplift in Southern Asia and the American west. J. Geophys. Res., 94, 18409 18 427, doi:10.1029/JD094iD15p18409.

Schmittner, A., T. M. Silva, K. Fraedrich, E. Kirk, and F. Lunkeit, 2011: Effects of mountains and ice sheets on global ocean circulation. J. Climate, 24, 2814-2829, doi:10.1175/2010JCLI3982.1.

Sepulchre, P., G. Ramstein, F. Fluteau, M. Schuster, J.-J. Tiercelin, and M. Brunet, 2006: Tectonic uplift and Eastern Africa aridification. Science, 313, 1419-1423, doi:10.1126/science.1129158.

Singh, H. K. A., C. M. Bitz, and D. M. W. Frierson, 2016: The global climate response to lowering surface orography of Antarctica and the importance of atmosphere-ocean coupling. J. Climate, 29, 4137-4153, doi:10.1175/JCLI-D-15-0442.1.

Sinha, B., A. T. Blaker, J. J. M. Hirschi, S. Bonham, M. Brand, S. Josey, R. S. Smith, and J. Marotzke, 2012: Mountain ranges favour vigorous Atlantic meridional overturning. Geophys. Res. Lett., 39, L02705, doi:10.1029/2011GL050485.

Takahashi, K., and D. S. Battisti, 2007a: Processes controlling the mean tropical Pacific precipitation pattern. Part I: The Andes and the eastern Pacific ITCZ. J. Climate, 20, 3434-3451, doi:10.1175/JCLI4198.1.

$\longrightarrow$, and $-2007 \mathrm{~b}$ : Processes controlling the mean tropical Pacific precipitation pattern. Part II: The SPCZ and the southeast Pacific dry zone. J. Climate, 20, 5696-5706, doi:10.1175/2007JCLI1656.1.

Trenberth, K., D. Stepaniak, and J. Caron, 2000: The global monsoon as seen through the divergent atmospheric circulation. J. Climate, 13, 3969-3993, doi:10.1175/1520-0442(2000)013<3969: TGMAST $>2.0 . \mathrm{CO} ; 2$.

Vecchi, G. A., and B. J. Soden, 2007: Global warming and the weakening of the tropical circulation. J. Climate, 20, 43164340, doi:10.1175/JCLI4258.1.

—, and A. T. Wittenberg, 2010: El Niño and our future climate: Where do we stand? Wiley Interdiscip. Rev.: Climate Change, 1, 260-270, doi:10.1002/wcc.33.

- B. J. Soden, A. T. Wittenberg, I. M. Held, A. Leetmaa, and M. J. Harrison, 2006: Weakening of tropical Pacific atmospheric circulation due to anthropogenic forcing. Nature, $\mathbf{4 4 1}$, 73-76, doi:10.1038/nature04744.

Walker, G. T., and E. W. Bliss, 1932: World weather V. Mem. Roy. Meteor. Soc., 4, 53-84.

Watanabe, M., and A. T. Wittenberg, 2012: A method for disentangling El Niño-mean state interaction. Geophys. Res. Lett., 39, L14702, doi:10.1029/2012GL052013.

, J. S. Kug, F. F. Jin, M. Collins, M. Ohba, and A. T. Wittenberg, 2012: Uncertainty in the ENSO amplitude change from the past to the future. Geophys. Res. Lett., 39, L20703, doi:10.1029/2012GL053305.

Wittenberg, A. T., 2002: ENSO response to altered climates. Ph.D. dissertation, Princeton University, 319 pp. [Available online at http://gfdl.noaa.gov/ atw/research/thesis.]

—, A. Rosati, N. C. Lau, and J. J. Ploshay, 2006: GFDL's CM2 global coupled climate models. Part III: Tropical Pacific climate and ENSO. J. Climate, 19, 698-722, doi:10.1175/JCLI3631.1.

Xu, H., Y. Wang, and S. P. Xie, 2004: Effects of the Andes on eastern Pacific climate: A regional atmospheric model study. J. Climate, 17, 589-602, doi:10.1175/1520-0442(2004)017<0589: EOTAOE $>2.0 . \mathrm{CO} ; 2$.

Zelle, H., G. J. van Oldenborgh, G. Burgers, and H. Dijkstra, 2005: El Niño and greenhouse warming: Results from ensemble simulations with the NCAR CCSM. J. Climate, 18, 4669-4683, doi:10.1175/JCLI3574.1. 